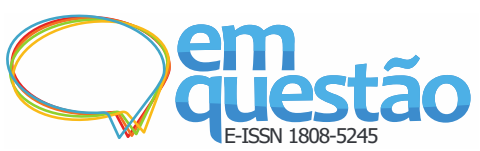

\title{
O TikTok como ferramenta de inovação em serviços de informação em bibliotecas
}

\author{
Diego Leonardo de Souza Fonseca \\ Doutorando; Universidade Estadual de Londrina, PR, Brasil; \\ diego.leonardo@uel.br; ORCID: https://orcid.org/0000-0002-0105-1577 \\ Maria Gabriella Flores Severo Fonseca \\ Doutoranda; Universidade de Brasília, DF, Brasil; \\ gabriellafloress@hotmail.com; ORCID: https://orcid.org/0000-0003-1487-0480
}

\begin{abstract}
Resumo: O estudo tem como objetivo analisar o posicionamento digital de algumas bibliotecas na rede social TikTok, observando o uso dessa plataforma como estratégia de inovação em serviços na perspectiva das novas tendências de consumo da informação. Trata-se de uma pesquisa descritiva, de abordagem qualitativa, cujo delineamento do estudo foi dividido em duas fases: pesquisa bibliográfica (levantamento de pesquisas e relatos de experiências sobre o tema) e levantamento dos perfis de bibliotecas na rede social que utilizam a plataforma. Foram analisados cinco perfis: Biblioteca Pública Sierra Madre, Biblioteca Pública de Vancouver, Biblioteca Pública de Iowa, Biblioteca Pública de Dover e a Biblioteca Pública de Calgary. O processo de análise da pesquisa sobre o posicionamento digital desses espaços foi realizado a partir de quatro aspectos: marketing, engajamento, interação com os usuários e produção de conteúdo. Observou-se que essas bibliotecas, aliando seu caráter profissional ao potencial de entretenimento da rede social TikTok, desenvolveram uma relação de interação e de engajamento com os seus usuários, o que gerou maior interesse pelos seus serviços de informação e produtos por meio do marketing digital. Tornaram-se, assim, inovadoras em seu posicionamento digital estratégico, acompanhando as novas tendências de consumo da informação pelos usuários.
\end{abstract}

Palavras-chave: Rede social; Inovação; Serviços de informação; Consumo da informação; Biblioteca

\section{Introdução}

$\mathrm{O}$ atual cenário mundial do consumismo, relacionado ao processo de desenvolvimento das tecnologias da informação e da comunicação, tem possibilitado o surgimento de novos serviços e produtos para o atendimento às demandas emergentes do mercado. Em um estudo recente da empresa de 
consultoria de mercado Nielsen IQ (2021), apontou-se que o consumo de produtos e serviços no comércio eletrônico (e-commerce) cresceu cerca de 51\% em 2020, com destaque para as plataformas digitais de compra em redes sociais - os marketplaces.

$\mathrm{O}$ crescimento do consumo de serviços e de produtos em âmbito digital demonstra uma tendência, que, há anos, vem sendo remodelada a partir da evolução das gerações sociais X, Y, Z e Alpha. Segundo Ceretta e Froemming (2011), Geração X é aquela nascida entre 1960 a 1980, a Geração Y, entre 1980 a 1995, a Geração Z, entre 1995 a 2010, e a mais recente, a Geração Alpha, refere-se aos nascidos a partir de 2010 .

Não obstante, a informação, como insumo e objeto de consumo, foi ampliando seus espaços de distribuição, de acesso, de uso e de apropriação. Os consumidores - os que a detém e consomem - diversificaram, também, seus espaços de busca. Esse processo de integração, entre a informação e os interesses individuais e os coletivos, denominado por Castells (2008) como sociedade em rede, trata-se de um espaço dinâmico de produção, de uso e de consumo da informação a partir das necessidades de cada indivíduo.

Nesse sentido, pode-se investigar o posicionamento das bibliotecas, caracterizadas como unidades de informação, em relação à evolução do uso e do consumo da informação. Isso porque os ecossistemas de inovação, principalmente em serviços de informação, têm projetado um conjunto de possibilidades viáveis para que as bibliotecas ampliem os seus nichos de interação com os seus usuários/consumidores.

Compreende-se, assim, que o planejamento das bibliotecas, voltado à inovação em serviços de informação no contexto digital, deve ser direcionado à compreensão dos interesses e das necessidades informacionais dos usuários/consumidores da informação.

Para isso, deve-se salientar o papel das redes sociais e do vasto campo da Web $2.0^{1}$ quanto à ampliação de estratégias para promoção de maior engajamento nos espaços digitais, expandindo seu nicho de interação e seu posicionamento de mercado.

Com base nessa intenção de diálogo com as novas tendências de 
consumo da informação a partir do uso das redes sociais no contexto das bibliotecas, investiga-se o uso da rede social TikTok, em bibliotecas, como ferramenta estratégica de inovação em serviços de informação. Assim, para essa pesquisa, os perfis das bibliotecas foram analisados, com base no seu posicionamento digital, sob quatro perspectivas: (i) engajamento; (ii) marketing; (iii) interação com os usuários; e (iv) produção de conteúdo.

\section{$2 O$ contexto da inovação em serviços}

A inovação, em uma abordagem conceitual, pode ser definida como a introdução de bens ou serviços a partir de um processo de aperfeiçoamentos significativos ou a disponibilização de novos recursos que visem esse fim (OCDE, 2015). Para Kampylis, Bocconi e Punie (2012) esse conceito, em linhas gerais, refere-se à necessidade de apresentar uma proposta nova para a resolução de um problema.

Na visão de Schumpeter (1988), a ação de "inovar" vai além da criação de um novo serviço e produto, orienta-se a um processo de mudança da cultura organizacional e do desenvolvimento econômico da sociedade. Nesse sentido, o autor salienta que a inovação é um processo complexo, que reúne métodos e estratégias capazes de desenvolver a economia a partir de uma visão mais empreendedora, originando ciclos econômicos.

O processo de inovação pode ser determinado por suas atividades científicas, tecnológicas, organizacionais, financeiras e comerciais. Ademais, a inovação pode ser classificada conforme a sua natureza: incremental (novo produto ou serviço que incorpora diferentes elementos) e disruptiva ou radical (transformação significativa no oferecimento de um novo serviço ou produto) (NUCHERA; SERRANO; MOROTE, 2002). O Manual de Oslo da Organização para a Cooperação e Desenvolvimento Econômico (OCDE, 2015) apresenta quatro tipos básicos de inovação: de produto; de processo; de marketing e organizacional.

Conforme ilustra Cooper (1998), a inovação apresenta um modelo multidimensional, cuja ilustração representa os três eixos tridimensionais de nivelamento: eixo do produto e do processo, o eixo do processo incremental e 
radical; o eixo das atividades (administrativa e tecnológica), como se pode observar na figura 1:

Figura 1 - Modelo multidimensional de inovação

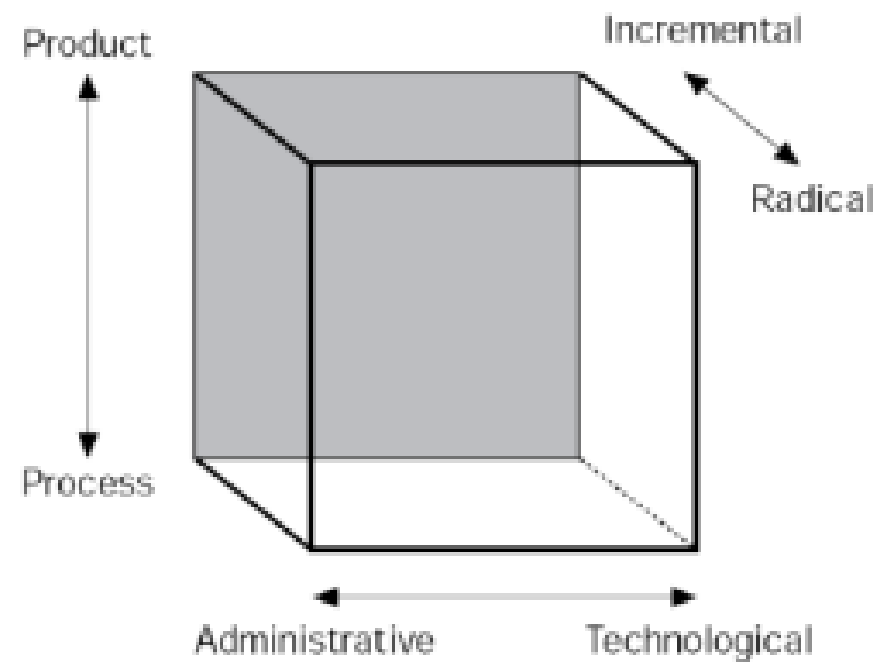

Fonte: Cooper (1998).

Compreende-se, assim, que a dinâmica durante os processos de inovação implica em multidimensões transversais, convergentes e divergentes de ações que resultam na geração de novos serviços e produtos. Isso dialoga com o que observam Salter e Tether (2006) sobre o setor de serviços como um cenário propicio para a geração de novas ideias e desenvolvimento de soluções para o crescimento econômico e tecnológico.

A partir da percepção do processo de inovação em serviços como conjunto complexo de estratégias de criação e de geração de novos conhecimentos para atender a diferentes demandas de aquisição, deve-se levar em consideração que os interesses do mercado são dinâmicos e diversificados (MILES, 2007).

Além disso, vale salientar, conforme pontua Barata (2011), que o setor de serviços se caracteriza por ser extremamente heterogêneo, intangível e atuante em diferentes setores econômicos da sociedade, tendo como enfoque atender às demandas dos clientes e usuários.

Para Bernardes e Bessa (2007), esse tipo inovação trata-se de um processo complexo, pois a produção de novos serviços é mais difícil de 
mensurar; e a intangibilidade de um serviço denota um maior aprofundamento nas atividades de Pesquisa e Desenvolvimento (P\&D).

\subsection{Inovação em bibliotecas}

No contexto das bibliotecas, a inovação surge como uma via fértil de possibilidades para a criação de serviços e de produtos informacionais. De acordo com Soto e Suescún (2015), o processo de inovação no planejamento das bibliotecas pode ser uma ferramenta fundamental para tornar o seu espaço mais produtivo, criativo e atual. Isso porque, segundo Lankes (2016), essa mudança de postura para atrair a atenção do usuário visa atender a evolução da sua demanda por informação.

Apesar de existirem barreiras para a plena efetivação do processo de inovação nas bibliotecas, como o extenso número de procedimentos burocráticos, a falta de infraestrutura, a carência de recursos humanos e financeiros, dentre outros (NEVES, 2018), é necessário compreender as bibliotecas como organizações que precisam se posicionar estrategicamente para atender e acompanhar a evolução da demanda informacional.

Isso porque, conforme observam Zaninelli, Nogueira e Horimi (2019), na sociedade contemporânea, a oferta de serviços inovadores é uma condição básica de sobrevivência para as instituições, principalmente para quem trabalha com a gestão e o uso da informação.

Posto isto, compreende-se que as bibliotecas são unidades de informação que, durante décadas, conseguiram se adaptar às mudanças sociais e tecnológicas, ao passo que a oferta de serviços e de produtos informacionais foi sendo modificada ao longo dos tempos para atender a essa evolução de necessidades dos seus usuários.

Desta maneira, observa-se que o processo de inovação em serviços na biblioteca vem acompanhando a própria evolução das tecnologias de informação e do mercado. De acordo com Corrêa e Garcia-Quismondo (2020), o desenvolvimento tecnológico e a evolução da internet, bem como o surgimento dos movimentos de acesso aberto, exigiram das bibliotecas a ampliação da sua atuação no âmbito digital por meio de novos serviços informacionais. 
Destarte, entende-se que as bibliotecas estão inseridas em um contexto gradual de transformações constantes quanto ao seu posicionamento mercadológico, haja vista que elas são espaços de geração de novos conhecimentos que utilizam a informação como insumo estratégico de inovação (LANGEN; MUSSARELI; CARLOS, 2020).

Desse modo, alude-se que a inovação em serviços na biblioteca deve ser pensada para o consumidor da informação, logo, o usuário precisa ser o componente central do processo de inovação, o que se refere a uma estratégia de análise bastante pertinente para inovar em serviços. Portanto, entende-se que as bibliotecas, como espaços criativos, devem desenvolver serviços e produtos de informação focados na perspectiva de consumo do usuário/consumidor.

\section{Informação e consumo}

A sociedade contemporânea advém de um processo transformador no seu modo de consumir, captar e utilizar os bens de consumo e de produção. Essa alteração de comportamento, desde a Revolução Industrial no século XVIII, vem assumindo diferentes estágios em um processo dinâmico de interesses e de necessidades, moldadas principalmente pelo fortalecimento do capitalismo (CAMPBELL, 2001).

Em meio a essa evolução histórica da relação entre consumo e produção, a informação assumiu uma importante identidade funcional no contexto das organizações na sociedade contemporânea, tornando-se um insumo estratégico básico de competitividade. Seu uso, como insumo estratégico, no mercado global, moldou as relações organizacionais, tecnológicas e comerciais, ao passo que assumiu um papel significativo na evolução do mercado de bens e serviços na sociedade (LEITÃO, 1993).

Esse cenário, já apontado por Castells (2008), configura-se como um espaço de relações e integrações de necessidades, demandas e compartilhamentos, cujo processo de interdependência entre indivíduos e organizações vem moldando as perspectivas de consumo de serviços e produtos. 
Na visão de Guerra (2011), o consumo é um termo representativo do processo de vinculação entre uma relação de interesse para adquirir um determinado bem ou produto com a oferta veiculada e propagada pelo mercado. Logo, de acordo com o autor, o consumo, tanto sob a perspectiva do produto como pelo serviço, é caracterizado por ações de uso e de apropriação, nas quais há a incidência de um fenômeno de pertencimento e satisfação.

Para Campbell (2001), o processo de produção de informação para atender determinada demanda de consumo configura-se em uma lógica de compartilhamento e disseminação, na qual a informação (insumo) é destinada a atender a um consumidor (usuário) sob a lógica do mercado. Essa espacialidade de integração, entre a informação e o consumo, funciona a partir de uma dinâmica de interesses com a finalidade de satisfazer às necessidades e aos desejos do consumidor.

Segundo analisa Leitão (1993), a gestão estratégica da informação para atender ao mercado consiste, basicamente, em definir ações e objetivos que busquem moldar a criação de novos serviços e produtos informacionais com base no perfil do usuário da informação. Sendo assim, observa-se que a relação entre o consumo e o mercado tende a ser orientada pela análise do comportamento do consumidor.

Nessa perspectiva, Solomon (2011) analisa que o comportamento dos consumidores está condicionado ao processo de aquisição de experiências que vivencia ao longo do seu cotidiano. Sobre o comportamento informacional do consumidor, Moura e Faria (2018) analisam que é motivado por um conjunto de fatores que influencia a sua visão de mercado e as suas necessidades de consumo: marketing em mídias sociais, propagandas, fontes de informação, serviços de recomendação na web, dentre outros. Pode-se, assim, inferir que a construção do comportamento informacional do consumidor da informação faz parte de um processo complexo que envolve o compartilhamento de informações e os núcleos de interesses regidos pelo mercado.

Os nichos dos padrões de consumo da informação estão cada vez mais imersos no contexto web. Para Faria (2018), as organizações estão buscando ampliar os seus investimentos para melhorar a interação no processo de 
consumo de bens e serviços, apostando no consumo informacional como estratégia de mercado.

$\mathrm{O}$ e-commerce ${ }^{2}$ e as plataformas de streaming ${ }^{3}$ são exemplos de nichos de mercado que estão utilizando a comunicação e o consumo de informação, com base na experiência dos usuários, para criar e oferecer serviços e produtos inovadores (FARIA, 2018). Essa realidade de unir os interesses do consumidor ao seu comportamento e as suas experiências de consumo tem transformado a maneira como as organizações estão produzindo novos serviços e produtos, principalmente nas redes sociais.

\subsection{Consumidores da informação}

Para Campbell (2001), o “consumidor”, por definição, pode ser representado por um grupo de indivíduos que regem os interesses econômicos e comerciais a partir das suas necessidades. O campo do consumo é bastante vasto, tendo no setor de serviços, principalmente nos serviços de informação, um nicho bastante atrativo e economicamente prospectivo.

De acordo com Amaral (2017), o consumidor da informação é o indivíduo que usa e se apropria da informação para atender as suas necessidades informacionais. Esse tipo de consumidor tem como interesses o acesso e o uso da informação como bens de consumo, portanto, compreende-se que o elo a interligar a necessidade e a demanda é a satisfação.

A teoria da "economia da atenção", criada pelo economista Herbert Simon, premiada no prêmio Nobel de Economia (1978), observa que a informação em grande quantidade pode vislumbrar um cenário de maiores incertezas sobre a escolha de um determinado objeto - essa base teórica, para o mercado, foi a precursora da denominada "economia da informação" - da qual o volume de informações passou a ser filtrado e analisado (RODRIGUES; ROSA, 2015).

Essa realidade tem mudado o comportamento dos consumidores da informação ao longo de décadas, alterando padrões de consumo, perspectivas de 
tendência por serviços de informação e o surgimento de interesses por novas demandas de tecnologias e apropriações em ambientes digitais de consumo.

Para Rodrigues e Rosa (2015), a evolução geracional da sociedade pode ser observada em todos os principais aspectos, os quais vêm ditando o cenário econômico e a construção de tendências e perspectivas mercadológicas. Segundo Ceretta e Froemming (2011), o perfil das gerações foi sendo desenvolvido ao longo dos anos com base em um conjunto de diferentes elementos, bem como de aspectos e características que influenciaram esse processo de evolução: tecnologia, economia, comportamento social, costumes, contexto político-social, dentre outros.

Todo esse processo temporal na evolução das gerações sociais tem sido impactado, principalmente, pela evolução tecnológica e informacional, cuja influência não apenas remodelou tendências e comportamentos, mas também construiu uma relação de consumo. É o que Solomon (2011) analisa como a construção do hábito do consumidor a partir da percepção de novas preferências e necessidades, que passa a ditar seu comportamento de consumo.

A caracterização dos consumidores pode ser compreendida em cinco tipos: Os consumidores 1.0, 2.0, 3.0, 4.0 e 5.0. O consumidor 1.0 trata-se do consumidor que cresceu com o início da internet e com as primeiras compras online; o consumidor 2.0 é aquele que vivenciou a evolução da internet e o início do e-commerce; o consumidor 3.0 modifica seu comportamento em relação ao consumo, pois passou a ser mais engajado na proposição de escolha e melhorias para o seu serviço e produto; o consumidor 4.0 apresenta maior poder de decisão sobre seu consumo, pois é totalmente inteirado sobre os processos tecnológicos; e o consumidor 5.0 é o que existe atualmente, cuja influência e tendência de comportamento molda o mercado - é denominado de "consumidor radical” (CESTARI JUNIOR, 2016).

A tendência de consumo por serviços de informação, mais especificamente na web, retrata uma perspectiva comportamental em ascensão nos próximos anos, observando o crescimento do mercado digital. De acordo com a Pesquisa Pulso Empresa do Instituto Brasileiro de Geografia e Estatística (IBGE), realizada em 2020, o panorama de inovações para os próximos 15 anos 
está atrelado ao mercado digital, focado principalmente nas plataformas de mídias sociais, aplicativos de e-commerce e jogos eletrônicos (IBGE, 2020).

Esse panorama, não somente apresenta um cenário atual, como prospecta para um cenário futuro uma tendência de demanda por serviços que atenderá um consumidor da informação bem mais alinhado ao mercado digital e as experiências construídas e possibilitadas por meio das redes sociais.

\section{TikTok}

A rede social surgiu em 2014, ainda com o nome de Musical.ly, tendo a versão comprada pela empresa chinesa ByteDance, em 2016, por cerca de US\$ 1 bilhão, no qual foi fundida com o aplicativo Douyin, dando origem ao TikTok. Trata-se de uma rede social de vídeos curtos para uso em smartphones, estando disponível nos sistemas operacionais Android (Google) e iOs (Apple). A dinâmica de funcionamento permite a criação de vídeos de até 60 segundos, que podem ser publicados em um feed (área de conteúdo) pelo usuário da plataforma (WANG, 2020).

A popularidade do TikTok fez com que ele se tornasse o segundo aplicativo mais baixado na App Store em 2019, superando grandes concorrentes como o Instagram e o Facebook ${ }^{4}$. De acordo com Wang (2020), o crescimento do TikTok no cenário das redes sociais deu-se, basicamente, por dois motivos: os vídeos curtos, que captam a atenção do usuário; e a produção criativa de conteúdo. Nessa mesma lógica de percepção, Monteiro (2020) analisa que a produção de conteúdo criativo no TikTok atraiu um nicho de usuário bem característico das redes sociais: o usuário ativo.

Por ser relativamente novo, o TikTok é uma rede social que vem ganhando espaço no mercado digital, influenciando o comportamento de usuários, consumidores e empresas. Para Wang (2020), a influência midiática do TikTok é bastante presente na geração $\mathrm{Z}$ e, mais recentemente, na geração Alpha. Porém, é possível observar que ela vem ganhando espaço no público mais adulto (geração X e Y), influenciado, principalmente, pelos investimentos das grandes marcas na plataforma. 
A participação ativa de celebridades e famosos produtores de conteúdo na rede social (denominados tiktokers) também são fatores que impulsionam a participação e o engajamento dos usuários na interação ativa com a plataforma, o que para o business (negócios) é extremamente valioso e promissor (MONTEIRO, 2020). Essa aproximação de relacionamento é uma característica bastante presente nas redes sociais, e que vem ditando tendências de consumo e comportamentos de consumidores.

Barin, Ellensohn e Silva (2020) analisam o uso do TikTok como ferramenta de suporte para o contexto educacional, tendo uma importante funcionalidade para os processos de ensinoaprendizagem, principalmente no ambiente de ensino remoto. Essa percepção de uso do TikTok denota uma ampliação dos nichos de abrangência dos recursos e das ferramentas da rede social, indo além do ambiente de entretenimento.

Portanto, observa-se que o universo de possibilidades apresentado pelo TikTok pode vir a desencadear um cenário de potencialidades de tendências de mercado, capaz de ditar comportamentos e influenciar relações entre o consumidor e o ambiente digital.

De acordo com os estudos da empresa Rock Content (BORRAGINI; SATHLER, 2020), o público-usuário do TikTok é caracterizado em dois tipos: usuários ativos (frequência de uso de até 8 horas por dia) e os usuários moderados (frequência de uso de até 4 horas por dia). Além desses principais tipos de usuário, a rede social também conta com usuários que utilizam a plataforma somente para acessar perfis de interesse em horários pontuais do dia, sem necessariamente produzir conteúdo (BORRAGINI; SATHLER, 2020).

Esse panorama apresentado pelo TikTok impulsionou o marketing digital realizado por diversas marcas, principalmente com foco no engajamento direcionado ao público mais jovem, tendo se mostrado uma estratégia digital de grande relevância para o atual mercado digital.

Para Wang (2020), a dinâmica de comportamento do usuário no TikTok é ditada pela produção de conteúdo na rede social, incentivado por celebridades (tiktokers) e empresas de diferentes ramos do mercado. Essa relação entre a produção de conteúdo e o perfil do consumidor é atenuada pelo boom de 
informação produzido, em todo tempo (e em tempo real), na plataforma, gerando um alto fluxo de engajamento e um compartilhamento de informação extremamente rápido.

Segundo analisa a Rock Content (BORRAGINI; SATHLER, 2020), a expectativa é que o TikTok aumente o seu alcance em até 78\% nos próximos 2 anos, com uma estimativa de até US\$ 100 milhões de investimento injetados por empresas que estão otimizando a sua estratégia de marketing digital e apostando no uso mais ativo da plataforma. Mais recentemente, em 2020, a empresa lançou a plataforma TikTok For Business, como estratégia para atrair empresas e investidores em um ambiente de marketplace para divulgação e promoção de serviços e produtos para parceiros comerciais.

As organizações estão investindo em inovação com base na criatividade no processo de produção de conteúdo. Para Monteiro (2020), a dinâmica de usabilidade do TikTok trouxe uma nova perspectiva de consumo da informação, cuja participação do consumidor, seja ativo ou moderado, é importante para o mercado digital, pois orienta tendências de criação de novos serviços e produtos baseados nas suas preferências e experiências.

Analisando essa perspectiva de Monteiro (2020), infere-se que o consumidor da informação no cenário atual está mais inclinado a ser coparticipante do processo de construção do serviço e do produto desenvolvido. Para tal, ressalta-se que as bibliotecas são organizações que também têm demandado a utilização de estratégias de análise de comportamento do consumidor da informação, tendo como objetivo a aproximação do usuário no mercado digital.

\section{Procedimentos metodológicos}

O percurso metodológico do estudo caracteriza-se, quanto ao objetivo, como uma pesquisa descritiva de abordagem qualitativa. O embasamento teóricoconceitual da pesquisa fundamentou-se nas produções cientificas das áreas da Ciência da Informação e da Gestão da Inovação. Quanto à natureza, trata-se de 
uma pesquisa básica para fins de análise e investigação com o propósito de gerar novos conhecimentos (GIL, 2007).

O processo de coleta dos dados foi definido em duas etapas: levantamento bibliográfico e análise dos perfis na rede social. Inicialmente, foi realizado um levantamento de pesquisas e relatos de experiência sobre a temática nas seguintes bases de dados: Portal de Periódicos da Coordenação de Aperfeiçoamento de Pessoal de Nível Superior (CAPES), Base de Dados Referencial de Artigos de Periódicos em Ciência da Informação (BRAPCI) e SciELO.

A estratégia de busca foi realizada a partir do uso das seguintes palavraschave: 'Biblioteca', 'TikTok', 'Mídias sociais' e 'Consumo de informação'. A temporalidade de busca foi livre, sem filtragem por ano de publicação. Após essa primeira etapa, não houve nenhum retorno de resultado de pesquisas na literatura científica brasileira.

Na segunda etapa, realizou-se um levantamento dos perfis de bibliotecas no campo de busca do TikTok a partir do uso das seguintes hashtags (palavraschaves): \#biblioteca, \#bibliotecário, \#bibliotecabrasil, \#bibliotecanotiktok, \#librarianship, \#librariesoftiktok, \#library e \#booktok (termo popularizado na rede para promover ações de leitura e serviços em bibliotecas).

Após esse levantamento, foram recuperados cinco perfis na rede social: Biblioteca Pública Sierra Madre (@sierramadrepubliclibrary), Biblioteca Pública de Vancouver (@vancouverpubliclibrary), Biblioteca Pública de Dover (@doverpubliclibrary),Biblioteca Pública de Iowa (@iowacitypubliclibrary)e a Biblioteca Pública de Calgary (@calgarylibrary). Coube aqui analisar somente bibliotecas institucionalizadas, desconsiderando perfis pessoais de bibliotecários e de influenciadores digitais (Booktubers). Ressalta-se aqui uma observância sobre a ausência da atuação das bibliotecas brasileiras na rede social, não sendo identificadas em nenhuma combinação de busca. 


\section{$6 \mathrm{O}$ posicionamento das bibliotecas no TikTok}

Com base no levantamento realizado no campo de busca do TikTok, foi possível identificar e analisar os perfis de bibliotecas que atuam na promoção de serviços e produtos por meio da plataforma. O processo de análise do posicionamento digital das bibliotecas foi realizado a partir de quatro aspectos, baseados em princípios e estratégias do marketing digital (CINTRA, 2010; TORRES, 2018): (i) engajamento, (ii) marketing, (iii) interação com os usuários; e (iv) produção de conteúdo.

O engajamento consiste na relação de aproximação e de ligação estabelecida entre a biblioteca e o usuário, principalmente pela coparticipação nos posts. O marketing, para fins de análise, refere-se ao processo de divulgação e à promoção de serviços e produtos da biblioteca. A interação com os usuários foi analisada pela frequência de comentários e de curtidas (likes) nas postagens. A produção de conteúdo refere-se ao quantitativo de postagens realizadas pela biblioteca.

O processo de análise do estudo foi realizado a partir dos seguintes parâmetros: quantitativo de seguidores, quantidade de perfis seguidos, quantitativo de comentários e de interações (mentions), quantitativo de produção de conteúdo (postagens), quantitativo de visualizações e de likes ('gostei') por vídeo no perfil. O período de análise foi realizado entre os dias 07 e 12 de junho de 2021. Ao longo desse tópico, apresentam-se as tabelas abaixo com as referidas análises realizadas para cada perfil.

Na tabela um, analisa-se o perfil da Biblioteca Pública Sierra Madre (@sierramadrepubliclibrary),conta criada em maio de 2020.

Tabela 1 - Análise do perfil da Biblioteca Pública de Sierra Madre

\begin{tabular}{l|l}
\hline \multicolumn{2}{c}{$\begin{array}{c}\text { Biblioteca Pública de Sierra Madre } \\
\text { @sierramadrepubliclibrary }\end{array}$} \\
\hline Parâmetros por números & Dados \\
\hline Seguidores & 762 perfis \\
\hline Perfis que segue & 117 perfis \\
\hline Comentários e interações (mentions) & 196 interações \\
\hline Postagens & 56 vídeos \\
\hline Visualizações & 131.576 visualizações \\
\hline 'Gostei' (likes) & 5.948 likes \\
\hline \multicolumn{2}{c}{}
\end{tabular}


A Biblioteca Pública de Sierra Madre fica localizada no condado de Los Angeles, Califórnia, nos Estados Unidos, e atende a um público diversificado, em sua maioria, jovem. Nesse espaço, desenvolvem-se atividades de leitura, jogos, e ações culturais junto à comunidade local.

Conforme se pode visualizar na Tabela 1, o perfil da biblioteca no TikTok (@sierramadrepubliclibrary) apresenta excelentes índices de engajamento, observando que a quantidade de visualizações possui uma quantidade expressiva de comentários e de interações dos usuários na plataforma.

Quanto ao marketing, observou-se que a biblioteca promove campanhas para divulgar as novas aquisições e concursos de leitura para incentivar os usuários recém cadastrados a fazerem visitas guiadas na biblioteca. A produção de conteúdo é focada, principalmente, no conteúdo jovem e criativo, com vídeos de humor, inclusive convidando os usuários da biblioteca a participarem dos concursos promovidos.

No post "Library Services", é apresentado um desafio, demonstrando quais os serviços são oferecidos pela biblioteca, fazendo uma espécie de sátira com a visão da biblioteca como um "espaço de silêncio". Identificou-se que a biblioteca, apesar de ser recente na rede social, vem realizando uma produção de conteúdo frequente relacionada, principalmente à divulgação dos serviços de informação.

Na tabela dois, analisa-se o perfil da Biblioteca Pública de Vancouver (@vancouverpubliclibrary), criado em setembro de 2020.

Tabela 2 - Análise do perfil da Biblioteca Pública de Vancouver

\begin{tabular}{l|l}
\hline \multicolumn{2}{c}{$\begin{array}{c}\text { Biblioteca Pública de Vancouver } \\
\text { avancouverpubliclibrary }\end{array}$} \\
\hline Parâmetros por números & Dados \\
\hline Seguidores & 245 perfis \\
\hline Perfis que segue & 26 perfis \\
\hline Comentários e interações (mentions) & 11 interações \\
\hline Postagens & 16 vídeos \\
\hline Visualizações & 5.561 visualizações \\
\hline 'Gostei' (likes) & 273 likes \\
\hline \multicolumn{2}{c}{}
\end{tabular}


A Biblioteca Pública de Vancouver está localizada na cidade de Vancouver, no Canadá, e apresenta em sua estrutura administrativa um total de vinte e uma bibliotecas que atendem toda a cidade. Os serviços e produtos da biblioteca possuem uma característica heterogênea, atendendo, em grande parte, estudantes, pesquisadores e trabalhadores locais.

Observa-se na Tabela 2 que os parâmetros sobre quantidade de seguidores e de postagens são relativamente baixos, se comparado a outros perfis. Apesar do engajamento não ser tão alto, observou-se que a biblioteca investe na divulgação de seus serviços, como observado no post "How we make our books more durable", no qual o funcionário da biblioteca apresenta um breve tutorial sobre como "encapar os livros" para torná-los mais duráveis (1.331 views).

Quanto à produção de conteúdo, observou-se que o quantitativo de postagens ainda é relativamente baixo (16 vídeos), o que pode ser explicado observando a quantidade elevada de interações com os usuários na plataforma (11 mentions). Observou-se, também, que a biblioteca é mais ativa em outras redes sociais, como no Instagram (11 mil seguidores) e no Facebook (10 mil curtidas), apresentando maiores engajamento e presença digital nessas redes sociais.

Infere-se que, por estar migrando recentemente, a tendência é que a frequência de postagens e a produção de conteúdo aumente no TikTok. Em seus vídeos com maior engajamento, ela divulga os novos livros adquiridos para o acervo e indica leituras para datas comemorativas.

Na tabela três, detalham-se os dados do perfil da Biblioteca Pública de Dover (@doverpubliclibrary), criado em junho de 2020.

Tabela 3 - Análise do perfil da Biblioteca Pública de Dover

\begin{tabular}{l|l}
\hline \multicolumn{2}{c}{$\begin{array}{c}\text { Biblioteca Pública de Dover } \\
\text { @doverpubliclibrary }\end{array}$} \\
\hline Parâmetros por números & Dados \\
\hline Seguidores & 4.088 perfis \\
\hline Perfis que segue & 107 perfis \\
\hline Comentários e interações (mentions) & 655 interações \\
\hline Postagens & 80 vídeos \\
\hline Visualizações & 353.348 visualizações \\
\hline 'Gostei' (likes) & 68.7 likes \\
\hline \multicolumn{2}{c}{}
\end{tabular}


A Biblioteca Pública de Dover está localizada na cidade de New Hampshire, em Nova York, nos Estados Unidos. Com um acervo composto por livros, e-books, periódicos, materiais audiovisuais, jornais, dentre outros, a biblioteca disponibiliza diversos serviços e produtos para atendimento comunitário e áreas para a realização de atividades e eventos públicos.

Observa-se, na tabela 3, que a biblioteca possui uma atuação bastante ativa no TikTok, o que pode ser identificado pela quantidade de seguidores (4.088 perfis) e pelo número de visualizações (353.340 views). Esses dados refletem um importante engajamento do perfil com o público.

Quanto ao marketing, a biblioteca desenvolve em seu perfil algumas ações de marketing para promover o lançamento de livros, em especial os livros publicados por artistas da região. Nota-se, também, que a produção de conteúdo (80 vídeos) dialoga com o objetivo e a proposta do uso da rede social, a saber, o de apresentar as atividades e os serviços da biblioteca de forma criativa e interativa.

Dentre os vídeos, destacam-se dois que se tornaram virais (frequentemente compartilhados): o "The book must be decontaminated(...)", com 197 mil visualizações, e o "We're sorry for all the extra trips you hand to make", com 53 mil visualizações. Ambos os vídeos apresentam, de forma humorística e criativa, o processo de devolução de livros em meio ao período atual de pandemia do novo coronavírus (Covid-19) e os procedimentos de biossegurança da biblioteca no retorno presencial.

$\mathrm{Na}$ tabela quatro, analisa-se o perfil da Biblioteca Pública de Iowa (@iowacitypubliclibrary), criado em outubro de 2019.

Tabela 4 - Análise do perfil da Biblioteca Pública de Iowa

\begin{tabular}{l|l}
\hline \multicolumn{2}{c}{$\begin{array}{c}\text { Biblioteca Pública de Iowa } \\
\text { @iowacitypubliclibrary }\end{array}$} \\
\hline Parâmetros por números & Dados \\
\hline Seguidores & 406 perfis \\
\hline Perfis que segue & 67 perfis \\
\hline Comentários e interações (mentions) & 81 interações \\
\hline Postagens & 32 vídeos \\
\hline Visualizações & 17.159 visualizações \\
\hline 'Gostei' (likes) & 1.089 likes \\
\hline
\end{tabular}

Fonte: Dados da pesquisa. 
A Biblioteca Púbica de Iowa está localizada na cidade de Iowa, nos Estados Unidos. A Iowa City Public Library (ICPL) atende aos residentes da cidade, principalmente aos universitários, pesquisadores e trabalhadores da área da educação da Johnson Country e da University Heigths. Possui um acervo constituído por livros, revistas, jornais, mapas e materiais de informação para acesso público e gratuito em seus espaços de acesso.

Observa-se, na tabela 4, que o engajamento e alcance do perfil ainda é relativamente baixo: com 32 postagens (vídeos) e interação de 81 mentions em suas publicações. Essa baixa interação pode ser um reflexo na falta de frequência nas postagens.

No que se refere ao marketing, observou-se que a biblioteca direciona a produção do seu conteúdo para a divulgação dos espaços de leitura e das novas aquisições. Ela realiza muitas ações de marketing por meio dos denominados \#challengers (desafios), que são interações propostas no TikTok para movimentar a rede social produzindo vídeos sobre um determinado tema.

No vídeo "Why do need libraries when we can just google everything now anyway?", que possui 1.370 visualizações, é apresentado uma sátira sobre a importância do bibliotecário na busca pela informação. Salienta-se, porém, que não há vídeos referentes a interações com os usuários no espaço da biblioteca, como foi identificado em outros perfis.

Na tabela cinco, observa-se o perfil da Biblioteca Pública de Calgary (@calgarylibrary), criado em abril de 2020.

Tabela 5 - Análise do perfil da Biblioteca Pública de Calgary

\begin{tabular}{l|l}
\hline \multicolumn{2}{c}{$\begin{array}{c}\text { Biblioteca Pública de Calgary } \\
\text { acalgarylibrary }\end{array}$} \\
\hline Parâmetros por números & Dados \\
\hline Seguidores & 5.423 perfis \\
\hline Perfis que segue & 241 perfis \\
\hline Comentários e interações (mentions) & 865 interações \\
\hline Postagens & 88 vídeos \\
\hline Visualizações & 469.142 visualizações \\
\hline 'Gostei' (likes) & 77.200 likes \\
\hline
\end{tabular}

Fonte: Dados da pesquisa.

A Biblioteca Pública de Calgary está localizada na cidade de Calgary, em Alberta, no Canadá. Compõe um sistema de bibliotecas, incluindo uma 
Biblioteca Central e vinte e uma setoriais. É considerada uma das maiores bibliotecas do Canadá, cujo atendimento é extensivo para todas as principais categorias e tipologias de usuários da cidade, disponibilizando um acervo composto por livros, revistas, jornais, materiais eletrônicos, salas de jogos, brinquedoteca, atividades educativas, dentre outros serviços e produtos.

De acordo com a tabela 5, observa-se que a biblioteca possui um alto engajamento na rede social, identificado a partir do seu fluxo de interação bastante consistente entre os seguidores: 469.142 visualizações e 77.200 'gostei' no perfil. Esse engajamento é um reflexo na frequência de produção de conteúdo no perfil, que utiliza muitas hashtags para impulsionar a divulgação das postagens.

Apesar de ser um perfil recente, observa-se, através da sua produção de conteúdo, que a biblioteca oferece diferentes formas de abordagem em seus vídeos, principalmente direcionado para o público mais jovem e para os grupos de minorias: LGBTQI+, comunidades de refugiados, negros e latinos.

No vídeo "Celebrate your cultural heritage with us using the hashtag \#RockYourMocs", um dos mais engajados no perfil, com 41.5 mil visualizações, apresenta o uso de sapatos indígenas como identificação cultural. Em outro vídeo, “Come on y'all, study pods are for studying”, os bibliotecários promovem o lançamento do podcast da biblioteca a partir de uma sátira, simulando uma conversa entre os usuários. O marketing é frequentemente utilizado pela biblioteca para realizar a promoção de serviços, tais como o podcast, bem como a divulgação de novos livros e revistas adquiridas no acervo.

\section{Considerações finais}

Como apresentado, a pesquisa conseguiu identificar bibliotecas estrangeiras públicas ( 3 bibliotecas estadunidenses e 2 bibliotecas canadenses) que utilizam o TikTok de forma ativa, aliando o aspecto profissional ao entretenimento promovido por essa rede social. Ao analisar os perfis dessas bibliotecas, percebeu-se maior engajamento dos usuários a partir da produção de conteúdo por meio do marketing digital, publicado por meio dos vídeos de curta duração, 
com considerável número de visualizações, de interações (mentions), de quantidade de seguidores e de 'gostei' (likes).

Esse contexto de engajamento, possibilitado pelo TikTok, pode denotar uma seara passível de investimento em planejamento digital por parte das bibliotecas, no qual seja possível potencializar a divulgação da marca (branding), a promoção de serviços e produtos e a melhoria no engajamento com novos usuários-consumidores de informação.

Vale salientar que a maioria dos perfis analisados foram criados durante o período inicial da pandemia da Covid-19, no ano de 2020, exceto o perfil da Biblioteca Pública de Iowa, criado em 2019. Pode-se inferir que, no cenário da pandemia, a necessidade de aperfeiçoar a aproximação com o usuário em tempo de confinamento e de distanciamento social influenciou as bibliotecas a investirem no seu planejamento de posicionamento digital para uma rede social mais interativa, recente e popular.

Foi possível observar, durante o processo de coleta e análise de dados na pesquisa, a ausência da atuação de bibliotecas brasileiras na rede social. Esse cenário pode ser explicado por dois motivos: o período recente de criação do TikTok ou a falta de um planejamento estratégico de mídias por parte das bibliotecas. Observa-se que o TikTok é uma rede social que chegou com maior frequência, primeiro, em países como os EUA, Canadá e alguns da Europa, chegando com maior aderência no Brasil apenas em 2020. Essa diferença de cronologia no contato com a rede social talvez seja um fator que aproximou, primeiro, o TikTok das bibliotecas estrangeiras.

No Brasil, as bibliotecas ainda se encontram bastante presentes em outras redes sociais, como Instagram e Facebook, no entanto, não se observa, ainda, a mesma atuação no TikTok. Como sugestão de estudo, recomenda-se o uso do TikTok como uma ferramenta estratégica potencialmente inovadora no meio digital, principalmente para melhorar o posicionamento digital da biblioteca para gerar inovações em serviços de informação.

Diante disso, entende-se que esse tipo de posicionamento digital - ao ingressar em uma nova rede social - representa uma estratégia de inovação para dialogar com as novas tendências de consumo da informação, uma vez que as 
bibliotecas são organizações adaptáveis e que devem atuar, de forma holística e estratégica, para acompanhar o processo de evolução comportamental do seu usuário.

Compreende-se, portanto, que o Tiktok, como ferramenta para o uso estratégico dos recursos de marketing digital, pode ser uma ferramenta potencialmente vantajosa e competitiva para inovar no oferecimento de serviços e produtos de informação nas bibliotecas, fortalecendo o interesse desses consumidores da informação pelos serviços oferecidos por essas unidades de informação e, ao mesmo tempo, atendendo às demandas e às necessidades informacionais dos usuários.

\section{Referências}

AMARAL, S. A. do. Usuários, consumidores da informação e unidades prestadoras de serviços informativos na perspectiva de marketing. Transinformação, Campinas, v. 29, n.1, p. 27-30, jan./abr. 2017.

BARATA, J. M. M. Inovação em serviços: conceitos, modelos e medidas: uma aplicação ao sector bancário. Lisboa: Teaching Economisc Working Papers, 2011.

BARIN, C. S.; ELLENSOHN, R. M.; SILVA, M. F. O uso do TikTok no contexto educacional. Renote - Revista Novas Tecnologias na Tecnologia, Porto Alegre, v. 18, n.2, p. 630-639, dez. 2020.

BERNARDES, R. C.; BESSA, V. Novos campos teóricos e desafios métricos nos estudos de inovação entre indústria e serviços. In: BERNARDES, R.; ANDREASSI, T. (org.). Inovação em serviços intensivos em conhecimento. São Paulo: Saraiva, 2007.

BORRAGINI, H.; SATHLER, R. Marketing no Tik Tok. [S. l.]: Rock Content, 2020.

CALGARY PUBLIC LIBRARY. Calgary storie. 2021. Disponível em: https://calgarylibrary.ca/connect/calgary-story/. Acesso em: 31 jan. 2021.

CAMPBELL, C. A ética romântica e o espírito do consumismo moderno. Rio de Janeiro: Rocco, 2001.

CASTELLS, M. A sociedade em rede: a era da informação: economia, sociedade e cultura. 11. ed. São Paulo: Paz e Terra, 2008. 
CERETTA, S. B.; FROEMMING, L. M. Geração Z: compreendendo os hábitos de consumo da geração emergente. RAUnP - A Revista Eletrônica do Mestrado em Administração da Universidade Potiguar, Natal, v. 3, n. 2, p. 15-24, abr./set. 2011.

CESTARI JUNIOR, R. Entenda como se deu a evolução do consumidor e a transformação digital de cada perfil. Blog neoassist, [s. l.], 16 maio 2016. Disponível em: https://www.neoassist.com/blog/evolucao-do-consumidor/. Acesso em: 05 jun. 2021.

CINTRA, F. C. Marketing digital: a era da tecnologia on-line. Investigação, Franca, v. 10, n. 1, p. 6-12, 2010.

COOPER, J. R. A multidimensional approach to the adoption of innovation. Management Decision, [s. l.], v. 36, n. 8, p. 493-502, 1998.

CORRÊA, E. C. D.; GARCÍA-QUISMODO, M. Á. M. Tendências de inovação em serviços de bibliotecas universitárias: estudo de caso do CRAI Universitat Pompeu Fabra em Barcelona, Espanha. Em Questão, Porto Alegre, v. 27, n. 1, p. 430-455, jan./abr. 2021.

DOVER PUBLIC LIBRARY. Library home. 2017. Disponível em: https://www.dover.nh.gov/government/city-operations/library/. Acesso em: 31 jan. 2022.

FARIA, A. F. Consumo e informação: análise das práticas informacionais no contexto do comércio mobile a partir de aplicativos e redes sociais online. Bibliotecas Universitárias: pesquisas, experiências e perspectivas, Belo Horizonte, v. 4, n. 2, 2018.

GIL, A. C. Como elaborar projetos de pesquisa. 4. ed. São Paulo: Atlas, 2007.

GUERRA, R. S. Dimensões do consumo na vida social. Orientador: Alexandre de Antonio Cardoso. 2011. Tese (Doutorado em Sociologia) - Faculdade de Filosofia e Ciências Humanas, Universidade Federal de Minas Gerais, Minas Gerais, 2011.

IBGE. Pesquisa Pulso Empresa: indicadores de empresa no Brasil. 2020. Disponível em: https://covid19.ibge.gov.br/pulso-empresa/. Acesso em: 04 jun. 2021.

IOWA CITY PUBLIC LIBRARY. About Us. 2020. Disponível em: https://www.icpl.org/about/board. Acesso em: 31 jan. 2022.

KAMPYLIS, P.; BOCCONI, S.; PUNIE, Y. Towards a mapping framework of ICT: enabled innovation for learning. Luxembourg: Publications Office of the European Union, 2012. 
LANGEN, T. S. C.; MUSSARELI, F.; CARLOS, H. S. Tendências de inovação em bibliotecas mistas. South American Development Society Journal, [s .l.], v. 6, n.16, p. 295-320, 2020.

LANKES, D. Expect more: melhores bibliotecas para um mundo complexo. São Paulo, SP: Febab, 2016.

LEITÃO, D. M. A informação como insumo estratégico. Ciência da Informação, Brasília, v. 22, n. 2, p. 118-123, 1993.

MILES, I. Serviços e inovação na Europa. In: BERNARDES, R.; ANDREASSI, T. (org.). Inovação em serviços intensivos em conhecimento. São Paulo: Saraiva, 2007.

MONTEIRO, J. C. S. Tiktok como novo suporte midiático para a aprendizagem criativa. Revista Latino-Americana de Estudos Cientificos, Vitória, v. 1, n. 2, p. 5-20, 2020.

MOURA, M. A.; FARIA, A. F. Consumo e informação: análise de práticas informacionais no contexto do comércio móvel a partir de aplicativos e redes sociais on-line. In: ENCONTRO NACIONAL DE PESQUISA EM CIÊNCIA DA INFORMAÇÃO, 19., 2018, Londrina. Anais [...]. Londrina: UEL, 2018. p. 3273-3294.

NEVES, J. J. F. A inovação nas bibliotecas universitárias brasileiras: identificando o potencial inovador. 2018. Dissertação (Mestrado em Ciência da Informação) - Centro de Ciências da Educação, Universidade Federal de Santa Catarina, Florianópolis, 2018.

NIELSEN IQ. Tendências do varejo brasileiro: apresentação Nielsen IQ. In: Ranking ABRAS, [S. l.: $s . n$.], 2021.

NUCHERA, A. H.; SERRANO, G. L.; MOROTE, J. P. La gestión de la innovacíon y la tecnologia em las organizaciones. Madrid: Ediciones Pirámide, 2002.

OCDE. Manual de Oslo. 3. ed. São Paulo: FINEP, 2005.

RODRIGUES, A.; ROSA, J. L. Os novos consumidores de informação. Observatório da Imprensa, Rio de Janeiro, n. 856, 2015.

SALTER, A.; TETHER, B. Innovation in services: through the looking glass of innovation studies. New Delhi: Advanced Institute of Management, 2006.

SCHUMPETER, J. Teoria do desenvolvimento econômico. São Paulo: Abril Cultural, 1988. 
SOLOMON, M. R. O comportamento do consumidor: comprando, possuindo e sendo. 9. ed. Porto Alegre: Bookman, 2011.

SOTO, A.; SUESCÚN, S. Servicios inovadores em las bibliotecas públicas de Colombia: resultado de un estudio delphi. El profesional de la información, Barcelona, v. 24, n. 6, p. 778-786, nov./dez. 2015.

TECHTUDO. TikTok ultrapassa 1,5 bilhão de downloads e ainda supera o instagram. 2019. Disponível em:

https://www.techtudo.com.br/noticias/2019/11/tiktok-ultrapassa-15-bilhao-dedownloads-e-ainda-supera-o-instagram.ghtml. Acesso em: 31 jan. 2022.

THE CITY SIERRA MADRE. Biblioteca: catálogo e serviços. 2019.

Disponível em: https://www.cityofsierramadre.com/services/library. Acesso em: 31 jan. 2022.

TIKTOK BRASIL. O ano de 202 no TikTok Brasil. 2021. Disponível em: https://newsroom.tiktok.com/pt-br/o-ano-de-2020-no-tiktok-brasil. Acesso em: 31 jan. 2022.

TIKTOK FOR BUSSINESS. Gerenciamento de anúncios e marketing digital. 2019. Disponível em: https://www.tiktok.com/business/en-US. Acesso em: 31 jan. 2022.

TORRES, C. A bíblia do marketing digital: tudo o que você queria saber sobre marketing e publicidade na internet e não tinha a quem perguntar. 2. ed. São Paulo: Novatec, 2018.

VANCOUVER PUBLIC LIBRARY. About: library. 2016. Disponível em: https://www.vpl.ca/about. Acesso em: 31 jan. 2022.

WANG, Yunwen. Influence of camera view on TikTok users' presence, immersion, and adoption intent. Computers in Human Behavior, [s. l.], p. 106373,2020 .

ZANINELLI, T.; NOGUEIRA, C. A.; HORIMI, D. Inovação em serviços de informação no contexto da Biblioteca Central da Universidade Estadual de Londrina (UEL): uma análise do ponto de vista dos nativos digitais. Revista Brasileira de Biblioteconomia e Documentação, São Paulo, v. 15, n. 1, p. 228246, 2019. 


\title{
TikTok as a tool for innovation in library information services
}

\begin{abstract}
The study aims to analyze the digital positioning of some libraries in the social network TikTok, observing the use of this platform as an innovation strategy in services from the perspective of new trends in information consumption. This is a descriptive research of qualitative approach, whose study design was divided into two phases: bibliographic research (survey of research and experience reports on the theme) and survey of the profiles of libraries on the social network that use the platform. Five profiles were analyzed: Sierra Madre Public Library, Vancouver Public Library, Iowa Public Library, Dover Public Library, and Calgary Public Library. The research analysis process about the digital positioning of these spaces was carried out based on four aspects: marketing, engagement, interaction with users, and content production. It was observed that these libraries, by combining their professional character with the entertainment potential of the social network TikTok, developed a relationship of interaction and engagement with their users, which generated greater interest in their information services and products through digital marketing. They thus became innovative in their strategic digital positioning, following the new trends of information consumption by users.
\end{abstract}

Keywords: Social network; Innovation; Information services; Consumption of information; Libraries

Recebido: $24 / 06 / 2021$

Aceito: 04/10/2021

\section{Declaração de autoria}

Concepção e elaboração do estudo: Diego Leonardo de Souza Fonseca e Maria Gabriella Flores Severo Fonseca.

Coleta de dados: Diego Leonardo de Souza Fonseca.

Análise e interpretação de dados: Diego Leonardo de Souza Fonseca.

Redação: Diego Leonardo de Souza Fonseca e Maria Gabriella Flores Severo Fonseca.

Revisão crítica do manuscrito: Maria Gabriella Flores Severo Fonseca

\section{Como citar:}

FONSECA, Diego Leonardo de Souza; FONSECA, Maria Gabriella Flores Severo. O TikTok como ferramenta de inovação em serviços de informação em bibliotecas. Em Questão, Porto Alegre, v. 28, n. 2, e-116231, abr./jun. 2022. https://doi.org/10.19132/1808-5245282.116231 
O TikTok como ferramenta de inovação em serviços de informação em bibliotecas

Diego Leonardo de Souza Fonseca, Maria Gabriella Flores Severo Fonseca

${ }^{1}$ É considerada a evolução da Web 1.0, pois se caracteriza como uma segunda geração da internet.

${ }^{2}$ Comércio eletrônico.

${ }^{3}$ Modalidade de transmissão em tempo real.

${ }^{4}$ Pesquisa realizada pela empresa de tecnologia Senso Tower, em 2020. 